\title{
Disease Diagnosis and Management: The Experiences of Hemorrhoid Herbal Vendors and Customers in Oyo State, Nigeria
}

\author{
Abolaji Azeez \\ University of Ibadan \\ Uche C. Isiugo-Abanihe \\ University of Ibadan
}

\begin{abstract}
Hemorrhoids (or piles) are an anorectal condition that affects many individuals who do not necessarily seek medical support. Many who suffer from this condition resort to home treatment, especially cultural diagnosis and treatment. Consequently, an herbal remedy, popularly known as jedijedi drinks, has gained high patronage but with contested effectiveness. Thus, this study explored the diagnosis and use of hemorrhoid herbal remedy. Using a mixed-methods research design, information was elicited from those who used or sold the remedy at the three points of sales: 107 consumer respondents were surveyed and three herbal vendors were interviewed in Ibadan, Oyo Town, and Ogbomoso in Oyo State, Nigeria. The selection of the three herbal vendors was based on their popularity and patronage. Data interpretation included the use of chi-square and qualitative content analysis. Results revealed a high prevalence (71\%) of hemorrhoids among respondents who used jedijedi drinks for curative purposes; $90.7 \%$ of respondents claimed to know the risk factors for developing hemorrhoids. Specifically, respondents mentioned sugary and starchy substances $(77.8 \%)$, sitting for long periods of time (6.1\%), and stress $(8.1 \%)$ as perceived causes of hemorrhoids, and $9.2 \%$ asserted that the cause was preternatural. Respondents reported irregular menstrual cycle, an inability to sit or stand for long and erectile dysfunction as symptoms of hemorrhoids. The experience of erectile dysfunction was significantly related $\left(\chi^{2}=6.906\right)$ to respondents' marital status. Herbal vendors reported that the common diagnosis method was vendor-customer oral dialogue that determined the type of herbal remedy prescribed. Findings support the recommendation for public sensitization through mass media to reduce misconceptions about hemorrhoids that affect its management.
\end{abstract}

Keywords: Hemorrhoids, herbal remedy, herbal vendors, sexual activeness, sugary intake

\section{Introduction}

Hemorrhoids have been notorious among the Yoruba cultural group in Southwestern Nigeria (Osungunna, Oluremi, \& Talabi, 2010), probably because of the social and cultural effects attributed to them and the inability to correctly identify their risk factors (Azeez \& Isiugo-Abanihe, 2017). Hemorrhoids, as an anorectal condition, obstruct excretion and increase straining during a bowel

The survey was conducted with the financial support of the Council for the Development of Social Science Research in Africa (SGRT.45/T13). Also, we thank the United Nations Office on Drug and Crime for a travel grant to present the manuscript at the 2018 Centre for Research and Information on Substance Abuse conference. We appreciate Timothy Mclndoo for his editorial service. 
movement (Omole \& Adegboye, 2012). Typically, the blood vessels around the anus are ruptured and become hemorrhoids; they are commonly known as piles (jedijedi), especially when they become abnormal and unmanageable. Among the Yoruba, jedijedi can be literally translated as "consumer of the rectal system" (Akanle, Adesina, \& Fakolujo, 2017). The literary translation exposes social interpretation of disease, especially among the Yoruba, who label a disease based how it affects them.

Hemorrhoids are believed to cut across all demographic qualities, age, sex, social class, or status (Olateju, 2009). Many individuals suffer from the condition without seeking medical consultation (Kaidar-Person, Person, \& Wexner, 2007). Patients' reluctance to seek medical attention may be due to the embarrassment or fear, discomfort, and pain associated with the treatment (Kaidar-Person et al., 2007). This further enhances the proliferation of misconception about the disease (Lohsiriwat, 2015). Cleator and Cleator (2010) confirmed that hemorrhoids are a common cause of distress and treatments are often unsatisfactory as a result of recurrence or complications. Azeez and IsiugoAbanihe (2017) reported the majority of their respondents resorted to home treatments that entailed self-medication whether with modern or herbal medicine. This may explain why many patients seek herbal products for the management of hemorrhoids, which further confirms that culture and health are intertwined.

Culturally, there are misconceptions about the risk factors of the disease among the Yoruba. Recently, a study found that sugary or starchy intake was not, as popularly believed, a cause of hemorrhoids (Azeez \& Isiugo-Abanihe, 2017). Similarly, there are misconceptions about the symptoms of the disease: In general, herbal vendors believe that piles are multisymptomatic regardless of an individual's sex (Olateju, 2009), but among women, the symptoms may include black, odorous, irregular, or hindered menstrual flow (Olateju, 2009). Herbal vendors see hemorrhoids as a disease ranging from difficulty in stooling to difficulties with sexual activity (Olateju, 2009). Apart from the misconception about symptoms of the disease, herbal vendors mentioned other medical symptoms such as protruding anus and stool stained with blood. Contrary to the symptoms assumed among herbal vendors, medically, the symptoms include stooling repeatedly, blood in the stool, a burning sensation in or around the anus during or after bowel movements, and the anus making a steady staccato noise (Cleator \& Cleator, 2010).

Because sexual problems put strains on conjugal relationships, individuals are made to believe that hemorrhoids diminish sexual excitement (Zargooshi, 2008). It is said to be responsible for poor libido in women and weak erection in men prior to or during a sexual episode. This includes impotence in men, which carries a social stigma (Olateju, 2009; Alatise, Agbakwuru, Takure, Adisa, \& Akinkuolie 2010). In Nigeria, Zargooshi (2008) observed that one of the reasons for divorce was unconsummated marriage. This is also true for the Yoruba cultural tradition. Contrary to the belief that hemorrhoids reduce sexual ability, a stressful lifestyle precludes libido in humans (Concordia University Health Services, 2013). Also, issues relating to sexual problems are discussed covertly among adult victims, and these shameful experiences predispose individuals to seek traditional therapies.

Consequently, herbal medicine has played a significant role in the management of hemorrhoids. Oreagba, Oshikoya, and Amachree (2011), in their study of Herbal medicine use among urban residents in Lagos, Nigeria, reported that agbo jedijedi (herbal drink for piles) is the most frequently used herbal medicine preparation. Although their research indicated that $35 \%$ of their respondents used agbo jedijedi for treatment of the piles, its effectiveness was not confirmed. Of course, many patients living with hemorrhoids opt for alternative treatments. Osungunna et al. (2010) noted that hemorrhoids constitute one of the diseases for which herbal medicine has enjoyed unprecedented sales as a therapy in Southwestern Nigeria. 
There are many misconceptions about the causes of hemorrhoids and its treatments (Azeez \& IsiugoAbanihe, 2017). For example, many patients refuse surgical options due to their reservations about general anesthesia (Alatise et al. 2010). Studies have focused attention on various dynamics of hemorrhoids, including etymology of hemorrhoids (Kaidar-Person et al., 2007), the quality of herbal drinks (Osungunna et al., 2010; Oreagba et al., 2011), modern therapies and procedures (Ohning, Machicado, \& Jensen, 2009; Cleator \& Cleator, 2010), and misconceptions about hemorrhoids among police officers (Azeez \& Isiugo-Abanihe, 2017). At the same time, Akanle et al. (2017) explored the refusal of Western medicine practitioners to accept local narratives about hemorrhoids. The previous studies remain plausible, yet none of them has considered misconceptions about hemorrhoids among herbal medicine users. Against this backdrop, the purpose of this study was to understand the cultural misconceptions about hemorrhoids and factors that influence the type of therapy used among herbal vendors and their customers in the treatment of hemorrhoids.

\section{Methodology}

A mixed-methods approach was employed to interrogate the misconceptions about hemorrhoids and the influence of the misconceptions on the disease diagnosis among herbal vendors and the choice of treatment among herbal medicine consumers. The quantitative aspect of the study elicited data from herbal medicine consumers. It captured perceived causes, symptoms, and effects that could influence health-seeking behavior. The qualitative section was used to explore hemorrhoid diagnosis systems and attendant treatments offered by the herbal vendors.

This allowed the herbal vendors to share their experiences in the management of the disease. Thus, the mixed-methods approach served a complimentary purpose and helped gain an in-depth understanding and holistic view of the disease diagnosis and its management. The study was anchored in the rational choice theory. Coleman (1990) maintained that people act purposively toward a goal, with the goal (and thus the actions) shaped by values or preference. Individuals take decisions based on available resources. As a result, individuals weigh the cost and the benefits of an action before acting in a particular way. Thus, before an action is taken, the benefit is expected to outweigh the inherent cost. This explains why people living with hemorrhoids visit herbal vendors for diagnoses and treatments. Individuals adopt such health-seeking behaviors to stay healthy.

\section{Study Catchment Area}

The study was conducted among herbal medicine vendors and their customers in Oyo State who purchased and consumed the herbal drink, agbo jedijedi, for hemorrhoids. Oyo State is located in Southwest Nigeria with its capital at Ibadan. Oyo State covers $28,454 \mathrm{~km}^{2}$. The study cut across the state, to include Ibadan, Oyo Town, and Ogbomoso, especially where herbal drinks for piles are sold. The people are engaged in different occupational activities that predispose them to hemorrhoids.

The indigenes mainly comprise the Oyo, the Oke-Ogun, the Ibadan, the Ogbomoso, and the Ibarapa. These people are culturally known for the art of local medicine as a remedy for illness. In the urban slums, mobile and stationary herbal vendors are easily spotted at their different locations or joints. ${ }^{1}$ Some of the herbal medicines are acclaimed to be multifunctional. Perhaps such multifunctionality of herbal medicines builds confidence in their customers.

\footnotetext{
1 This refers to a relaxation center for people, especially men. At this location, different kinds of herbal drinks were available for sale. The drink could be alcoholic or nonalcoholic and served hot or cool.
} 


\section{Study Population and Sample Population}

The study was conducted among the herbal vendors and consumers of herbal medicine to treat hemorrhoids in Oyo State, Nigeria. The herbal vendors used indigenous knowledge in the preparation of the herbs that are usually in a liquid or powder form. Mostly, leaves, stalks, and roots were the major ingredients of the herbal remedy. People relied on the herbal vendors for the treatment of hemorrhoids and other ailments, which include infertility. Most of the herbal vendors often treat more than one disease. Also, women dominated in the sales of herbal drink. Sometimes, the women prepared a meat sauce alongside the herbal drink, which is usually bitter; the brand names of some jedijedi drinks make this clear (e.g., Alomo Bitters and Yoyo Bitters). The meat sauce is meant to reduce the bitterness. Customers are expected to consume the herbal medicine and the meat sauce simultaneously. Presumably, the sauce changes the bitter taste to mild taste easily and quickly.

Some of the herbal vendors are mobile, whereas others have stalls (also known as joints) where their customers meet them. Their joints are usually located strategically to capture the attention of their customers. The customers are free to relax and engage in discussions. The subjects of their discussions range from politics, fashion, and music, to the effectiveness of the herbal medicine, personal hemorrhoid episodes, and their general well-being. The customers are mostly male. Female customers are rarely found in such joints. Customers also used jedijedi cigarettes to treat hemorrhoids.

\section{Instrumentation}

The study used two instruments to elicit information from the respondents: a 43-item semistructured questionnaire and an in-depth interview (IDI) guide. The questionnaire was developed from the research objectives, the literature review and the theory underpinning the study. It contained four sections that captured different aspects of the scientific enquiry: (a) respondents' demography, (b) knowledge of hemorrhoids, (c) diagnosis of hemorrhoids, and (d) herbal medicines and treatment of hemorrhoids. Experts in the relevant academic fields validated the questionnaire, which include medical sociology and human nutrition. Administering the questionnaire, the researchers would read a question and the respondent would supply the answer orally while the researchers immediately documented the answer. The interview guide was designed to give direction to the discussion between interviewer and the herbal vendors. This guide centered on beliefs, perceptions, and experiences of herbal vendors in the diagnosis of hemorrhoids and determining the choice of herbal therapy. There were probing questions that elicited more information about aspects of the question that were not sufficiently explained. In pilot testing among a population with similar characteristics, the instruments satisfied face, content, and ecological validity. Pilot testing helped improve the instrument before the formal study.

\section{Data Collection}

This cross-sectional research design employed purposive sampling and a mixed-methods approach. Copies of the questionnaire were used to retrieve information on hemorrhoids in exit interviews among herbal medicine users. The study engaged snowballing and accidental sampling techniques because there was no sample frame. In the exit interview, 107 respondents were interviewed after they purchased and consumed herbal therapies for hemorrhoids. Also, three consenting, experienced herbal vendors were selected in the study area. The herbal vendors were purposively recruited into the study. Their selection was based on satisfaction of inclusion criteria, which included years of experience, proximity of the herbal vendors to towns, and willingness to allow their customers to be interviewed. 
To enlist the respondents, snowballing was adopted to locate centers/joints where herbal drinks were sold. Permission to conduct the study was sought from the three herbal vendors of the centers to incorporate eligible customers. For a respondent to be recruited into the study, he/she must have bought and used herbal drink for piles at the point of sale. Apart from that, the researchers duly informed respondents about the study and got their consent before each interview was conducted. The researchers read the questionnaire to respondents and filled in their responses, especially for customers/respondents who had no formal education. Each of the interview sessions lasted for at least $25 \mathrm{~min}$. The selection of participants for exit interview stopped at the saturation point, that is, when the majority of herbal drink consumers claimed they had already answered the questionnaire portion of the exit interview. The fieldwork lasted for four weekends. Data from 107 respondents were used for analysis in this category.

Three IDIs were conducted to explore traditional medicine with respect to knowledge and cultural perceptions about hemorrhoids. This includes three herbal vendors who were purposively selected from Ibadan, Ogbomosho, and Oyo Town. The herbal vendors were visited in their stalls. The study was introduced to them to gain informed consent. The consent was meant to include a scheduled time for the IDI and permission to recruit the vendors' customers into the study. All three herbal vendors consulted, and agreed to be interviewed on the first day they were consulted. Subsequently, the quantitative aspect of the study commenced.

For the purpose of analysis, quantitative data were cleaned to eliminate inconsistencies that could undermine validity. These data were finally analyzed SPSS Version 21. Analysis of data was undertaken using univariate frequency distribution and cross-tabulation of variables, whose associated influence impacted strongly on the study. Qualitative data were analyzed using Atlas.ti 6.2. The process began with the transcription and translation of computer recordings from the key informant interviews (KIIs). The next stage involved the coding of responses relevant to the focus of the study. Consequently, various themes were developed, which include oral diagnosis; diagnosis, treatment, and dosage; diagnosis and magical powers; and treatment by stages. Subthemes, such as the history of drug use for hemorrhoids, preexisting beliefs about hemorrhoids, nonadherence to dosage, and side effects of nonadherence, were discussed alongside the main themes. The software facilitated easy retrieval of quotes relevant to the study. In data presentation, both quantitative and qualitative data were presented simultaneously.

\section{Results}

\section{Characteristics of the Study Population}

Table 1 displays information on selected sociodemographic profiles of the respondents. About $96 \%$ of the respondents were male. The predominance of male respondents in the sample is as a result of the fact that more males than females are usually found in the public sphere in herbal centers. With respect to the age of the respondents, more than $55 \%$ of the respondents were between 26 and 35 years, with a mean age of 31 years. The respondents' age distribution showed that the respondents were in their sexually active age. Among the respondents, more than 55\% were married. The majority of the respondents had conjugal partners. Also, Table 1 revealed that a majority of the respondents belonged to the two dominant religions in Nigeria; however, a few (4\%) of the respondents were traditional worshippers. Table 1 also indicates that $35.5 \%$ of the respondents were graduates, and $1 \%$ of the respondents completed only primary school. In other words, the largest proportion of the consumers of herbal drink for piles graduated from higher institutions. Considering that Oyo State is predominantly inhabited by the Yoruba, a large majority of the respondents were Yoruba, representing about $86.9 \%$ of the sample population. Table 1 further details the employment status of the respondents (of whom $22.4 \%$ were not employed). 
Table 1. Selected Sociodemographic Characteristics of Respondents ( $\mathrm{N}=107)$

\begin{tabular}{|c|c|c|}
\hline Characteristic & Frequency & $\%$ \\
\hline \multicolumn{3}{|l|}{ Sex } \\
\hline Male & 103 & 96.3 \\
\hline Female & 4 & 3.7 \\
\hline \multicolumn{3}{|l|}{ Age } \\
\hline $16-25$ years & 27 & 25.2 \\
\hline $26-35$ years & 59 & 55.1 \\
\hline $36-45$ years & 16 & 15 \\
\hline$\geq 46$ years & 5 & 4.7 \\
\hline \multicolumn{3}{|l|}{ Marital status } \\
\hline Married & 59 & 55.1 \\
\hline Single & 48 & 44.9 \\
\hline \multicolumn{3}{|l|}{ Religious affiliation } \\
\hline Christianity & 58 & 54.2 \\
\hline Islam & 45 & 42.1 \\
\hline Indigenous religions & 4 & 3.7 \\
\hline \multicolumn{3}{|l|}{ Educational level } \\
\hline No formal education & 1 & 0.9 \\
\hline Primary level & 8 & 7.5 \\
\hline Secondary & 34 & 31.7 \\
\hline $\begin{array}{l}\text { National certificate in } \\
\text { education/ordinary national } \\
\text { diploma level }\end{array}$ & 21 & 19.6 \\
\hline $\begin{array}{l}\text { Higher national } \\
\text { diploma/bachelor's degree }\end{array}$ & 38 & 35.5 \\
\hline Master's or doctorate degree & 5 & 4.7 \\
\hline \multicolumn{3}{|l|}{ Ethnic group } \\
\hline Hausa & 2 & 1.9 \\
\hline Igbo & 12 & 11.2 \\
\hline Yoruba & 93 & 86.9 \\
\hline \multicolumn{3}{|l|}{ Occupational status } \\
\hline Employed & 83 & 81.6 \\
\hline Unemployed (student) & 24 & 22.4 \\
\hline
\end{tabular}

\section{Prevalence of Hemorrhoids, Knowledge, and Attitudes as Factors of Diagnosis}

With respect to respondents' illness experience, Table 2 presents the respondents who were suffering from piles and those who were not. About $71 \%$ of the respondents who purchased and consumed herbal drinks for piles were suffering, compared with $29 \%$ of the respondents who were not suffering from piles. This suggests that some people abuse herbal drinks for hemorrhoids, or they have other personal reasons for its consumption. Considering the awareness of respondent about the causes of hemorrhoids, larger percentage of the respondents (90.7\%) asserted that they were aware of the causes of hemorrhoids, whereas only a few (9.3\%) of the respondents could not affirm the causes of illness. 
Table 2. Percentage Distribution of Respondents According to Incidence of Piles

\begin{tabular}{lcc}
\hline Variable & Frequency & $\%$ \\
\hline Piles occurrence & & \\
Occurring & 76 & 71 \\
Not occurring & 31 & 29 \\
Causes of piles & & \\
Aware & 97 & 90.7 \\
$\quad$ Not Aware & 10 & 9.3 \\
Total & 107 & 100 \\
\hline
\end{tabular}

Figure 1 depicts respondents' perception of the causes of hemorrhoids. Over $77 \%$ of the respondents asserted that substances such as sugar and starch are responsible for piles. About $7 \%$ correctly reported some of the causes of piles are constipation and sitting for long, 8.1\% believed that stress is responsible, and $7 \%$ of the respondents maintained that food generally causes piles.

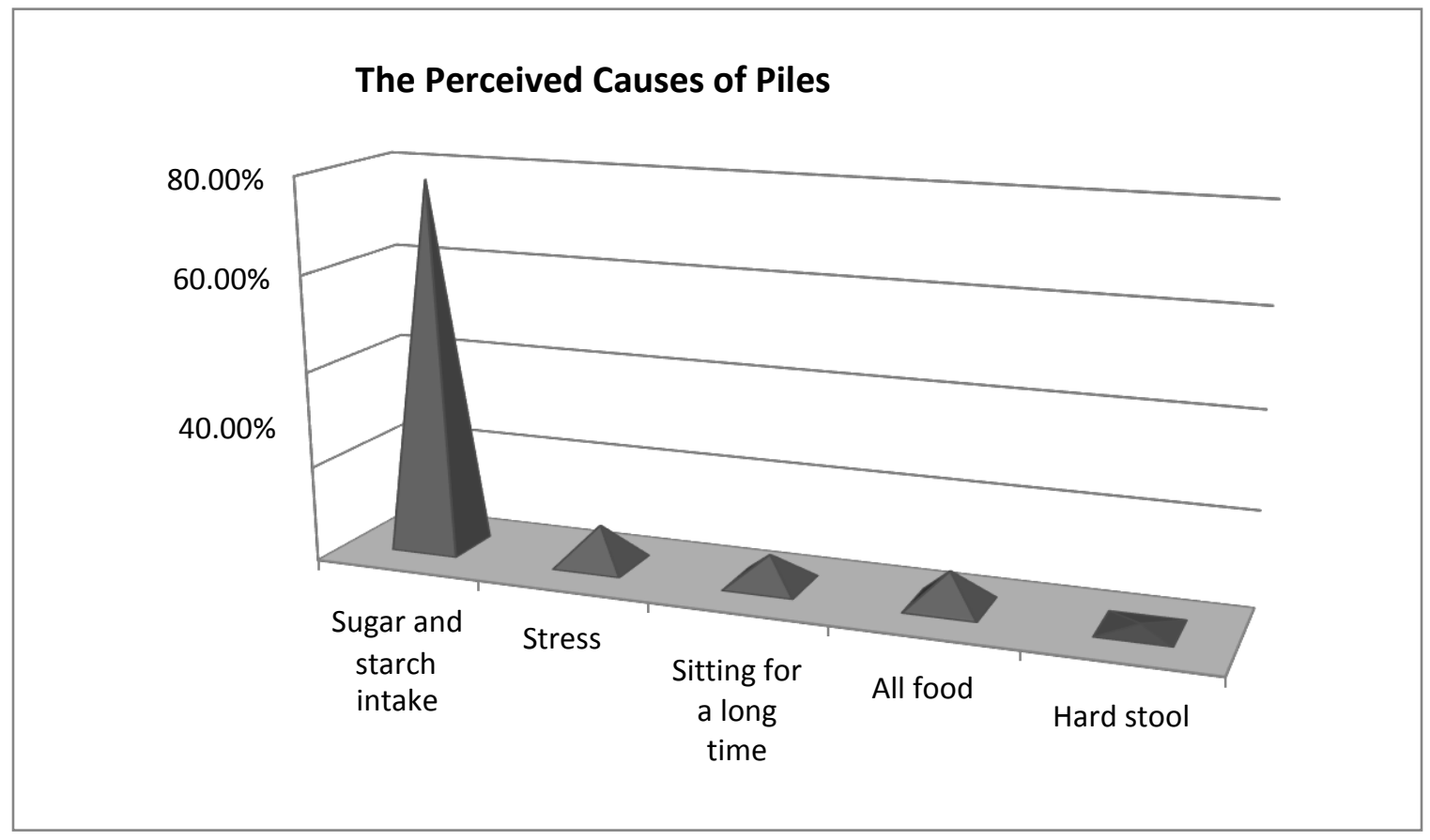

Figure 1. Distribution and Level of Awareness of the Perceived Causes of Piles ( $\mathrm{N}=107)$

Consequently, the results portray a widespread misconception about the risk factors of piles. In the process of oral diagnosis, the herbal vendors would confirm the sociocultural beliefs about the disease because the majority of the respondents presumed that sugary and starchy intake predispose individual to piles. The misconception corroborates the views of all herbal vendors interviewed, as vividly captured by one participant:

Excess meat causes jedijedi, anything starchy, such as garri flour, anything sweet causes piles. It is a popular disease. They know it and they take the herbal drink for jedijedi a lot 
because if the pile is too much in the body, it can cause malaria. It is not preternatural or from God. It is from the food we eat that lead to the pile, even beer can cause it. (KII/ female, herbal vendor/Yoruba/Oyo town/Oyo State)

Also, herbal vendors demonstrated that piles were an unpreventable disease for everyone. Its manifestation would be at various degree of severity. It was reported that all staple food would cause the disease. This places individuals in a dilemma and without the ability to stay healthy through dietary behaviour. One of the herbal vendors expressed her view as follows:

Many things cause pile; all foods especially solid ones, high carbohydrate concentration. In our place, when people want to take pap [i.e., maize flour custard locally produced especially among the Yoruba], they add sugar and pap itself contain a lot of carbohydrates, even when some people cook yam they add sugar to it.... The love and continuous consumption of red meat and rich tea are good for the body but cause piles. (KII/female/herbal vendor/Yoruba/Ibadan/Oyo State)

Figure 2 reveals perceptions about the preternatural causes of hemorrhoids by the respondents. More respondents (82.7\%) disagreed with the notion that God was responsible for hemorrhoids, while $10.6 \%$ upheld such a notion. Similarly, $85.5 \%$ of the respondents reportedly disagreed with the notion that sin could cause piles, to compare to the $5.9 \%$ who agreed. Data on the preternatural force as a cause of piles indicated that more than $82.8 \%$ of the respondents rejected the view, whereas only $9.2 \%$ agreed. The results show that few respondents believed that supernatural and preternatural forces cause hemorrhoids, which influenced their health-seeking behaviors.

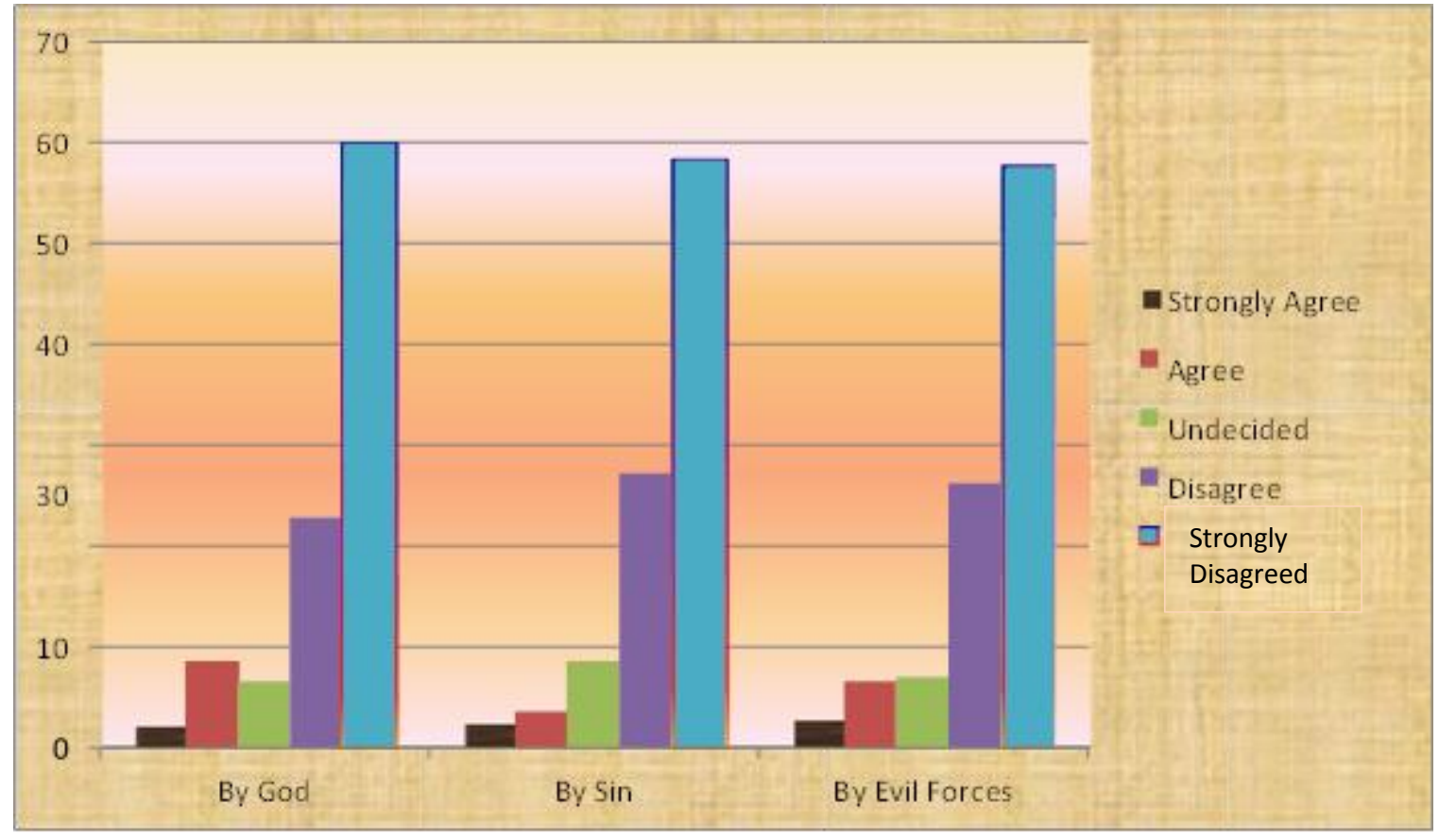

Figure 2. Perception About the Preternatural Causes of Piles $(\mathrm{N}=107)$ 
Herbal vendors agreed that preternatural and supernatural forces were not responsible for the illness. They identified that the illness emerged from individuals' consumption of unbalanced diets. Also, they mentioned the uniqueness of every individual's body. One of the herbal vendors shared a comprehensive thought in the following extract:

It is not from God although it is part of our body system. It is not caused by supernatural force. No, it's what we eat. For instance, my body system dislikes too much oil. If I take it before dusk I will be stooling with stomach pain or upset. There are some things that will not affect one's body. Not caused by sin. But if one goes to a party and takes bottles of beer, rice and meat; piles may occur. (KII/female/herbal vendor/Yoruba/Ibadan/Oyo State)

The female herbal vendor identified that the individual's body system would determine the risk factors for piles. In her case, excess consumption of oil would affect her health negatively. Her explanation showed that she was explaining piles alongside dysentery. Consequently, she is likely to diagnose dysentery as piles and give corresponding treatments.

Table 3 presents the perception about the effects of piles among respondents. Twenty-eight percent reportedly asserted that piles caused poor sexual strength. Similarly, 37.3\% of the married respondents and $16.3 \%$ of the single respondents maintained that piles were responsible for erectile dysfunction. Marital status was significantly related to the perception that piles cause erectile dysfunction. Thus, more married persons would assert that piles affect sexual strength negatively than unmarried singles. Also in Table 3, 38.3\% mentioned that piles caused backaches, whereas $62.7 \%$ of the married respondents rejected such view. Marital status was not significantly related to the belief that piles were responsible for backaches.

Table 3. Perceived Effects of Piles Among Respondents by Marital Status ( $\mathrm{N}=107$ )

\begin{tabular}{lccccc}
\hline Variable & Affirmed & Not Affirmed & $\boldsymbol{\alpha}^{2}$ & $\boldsymbol{d} \boldsymbol{f}$ & $\boldsymbol{p}$ \\
\hline Erectile & $30(28.0 \%)$ & $77(72.0 \%)$ & & & \\
dysfunction & $8(16.3 \%)$ & $41(83.7 \%)$ & 6.906 & 1 & 0.009 \\
Single & $22(37.3 \%)$ & $37(62.7 \%)$ & & & \\
Married & $41(38.3 \%)$ & $66(61.7 \%)$ & & & \\
Backache & $19(39.6 \%)$ & $29(60.4 \%)$ & 0.058 & 1 & 0.808 \\
Single & $22(37.3 \%)$ & $37(62.7 \%)$ & & & \\
Married & &
\end{tabular}

\section{Patronage of Herbal Medicine in the Treatment of Hemorrhoids}

Table 4 presents preferences in the treatments of piles among respondents. Most $(62.7 \%)$ of the respondents reportedly used herbal medicine for piles only, whereas $36.4 \%$ used both modern and herbal medicine together. Also, 20.5\% respondents used modern medicine due to proximity, whereas $49.5 \%$ respondents used herbal medicine owing to a jedijedi joint's proximity. The majority (75.7\%) of the respondents maintained that herbal medicine for piles was easy to use. Similarly, $67.3 \%$ of the respondents preferred an herbal drink, while $43.9 \%$ preferred herbal drink mixed with water, and $27.1 \%$ preferred herbal drink mixed with alcohol. 
Table 4. Distribution of Preference in the Treatments of Piles Among Respondents ( $\mathrm{N}=107)$

\begin{tabular}{lcc}
\hline Variable and Response & Frequency & $\%$ \\
\hline Treatment type & & \\
$\quad$ Modern medicine & 1 & 0.9 \\
Herbal medicine & 67 & 62.7 \\
Combined & 39 & 36.4 \\
Preferred therapy & & \\
$\quad$ Modern medicine & 10 & 8.5 \\
$\quad$ Herbal medicine & 80 & 75.5 \\
$\quad$ Combined & 17 & 16.0 \\
Close proximity & & \\
Modern & 22 & 20.5 \\
$\quad$ Herbal medicine & 53 & 49.5 \\
$\quad$ Both & 32 & 30.0 \\
Easy to use & & \\
Modern & 15 & 14.0 \\
$\quad$ Herbal medicine & 81 & 75.7 \\
$\quad$ Combined & 11 & 10.3 \\
Preferred herbal medicine & & \\
$\quad$ Herbal powder & 12 & 11.2 \\
$\quad$ Herbal drink & 72 & 67.3 \\
\hline
\end{tabular}

In Oyo Town, the Yoruba herbal vendors explained that some people would come for jedijedi herbal drink because they knew it would work. One vendor acknowledged that some of her customers would have used modern medicine, which would not work; thus, they resorted to herbal drink for piles. The patients with hemorrhoids were usually referred to the herbal vendor stall, where the transactions were done. To her, consistent patronage was due to the effectiveness of herbal remedies for piles. However, the patronage was not due to herbal vendors' proximity to people. Also, the level of patronage for herbal remedies for piles depended largely on the kind of herbal remedies. For instance, "it could be difficult to get the pap to mix with the powder before consumption, but for jedijedi drink, it is just a pour-and-drink, easy-to-use therapy" (IDI/female/herbal vendor/Yoruba/Ogbomoso/Oyo State).

This comment shows that the consumption of herbal medicine is based on quick access and easy administration of the herbal drink. In describing herbal drinks for piles, the vendor maintained that she usually sold alcoholic drinks, as well as nonalcoholic drinks for those who do not drink alcohol; some people will not even use the same cup used to serve the jedijedi drink with alcohol. From her experience, "my customers consumed both of them. They buy the two types. Everyone buys whatever he/she likes. People who take beer before will not refuse an alcoholic jedijedi drink" (IDI/female/herbal vendor/ Yoruba/Oyo Town/Oyo State). This suggests that herbal vendors use alcohol to prepare herbal drinks for piles to sustain the patronage of those who like alcohol. In Ogbomoso, the herbal vendor maintained that the water-mixed herbal drink was more effective than the alcohol-mixed drink. However, some customers would request an alcohol-mixed herbal drink even after they were persuaded not to take it. This suggests a sign of alcoholism.

Also, the herbal vendors in this study have their stalls situated in a location usually called an agbo jedijedi joint, where people gather, yet there are vendors who sell the medicine on the streets. The herbal vendor in Oyo shared that most of her customers were advised to use herbal medicine for piles especially when they could not see a positive outcome for very long after the medical procedure. Consequently, she permitted combined therapy: Her customers were allowed to use synthesized medicine and herbal medicine. For her, "they can use them together, but I do tell them to take herbal 
in the morning and modern medicine at night" (IDI/female/herbal vendor/Yoruba/Oyo Town/Oyo State). She claimed that there were other specialized therapies for critical hemorrhoid conditions. She explained that protrusion of the anus required herbal powder: The customers would mix the powder with pap before ingestion and apply some on his or her feces. Also, the vendor would give an herbal soap to individuals living with a protruding anus to clean up after stooling. The combination therapy would alleviate the severe hemorrhoids condition.

Table 5 presents the relationship between sociodemographics and preferred herbal drink. Close to half (42.4\%) of the Yoruba respondents used only the water-mixed herbal drink for piles, whereas $34.1 \%$ opted for the alcohol-mixed herbal drink. Also, 25.0\% of the Igbo respondents opted for the nonalcoholic herbal drink. The ethnic affiliation was significantly related to the kind of herbal drink. However, religious affiliation was not significantly related to preferred herbal drink. More than half (55.0\%) of respondents with an ordinary national diploma or a national certificate in education and $30.0 \%$ of respondents who had secondary education reportedly consumed the alcohol-mixed herbal drink. Half (50.0\%) of respondents with primary school education and $43.3 \%$ of the respondents who had completed secondary education preferred water-mixed herbal drink. Level of education was significantly related to the type of preferred herbal drink. Also, the herbal vendors pointed out and believed that everyone was their potential customer. This was evident in the following comment: "Everybody buys herbal medicine. Both literate and illiterate. People from all walks of life buy herbal medicine for jedijedi" (IDI/female/herbal vendor/Yoruba/Oyo Town/Oyo State).

Table 5. Cross-Tabulation of Sociodemographic and Preferred Herbal Drink ( $\mathrm{N}=107)$

\begin{tabular}{|c|c|c|c|c|c|c|}
\hline \multirow[b]{2}{*}{ Variable } & \multicolumn{3}{|c|}{ Preferred Herbal Drink } & \multirow[b]{2}{*}{$\chi^{2}$} & \multirow[b]{2}{*}{$d f$} & \multirow[b]{2}{*}{$p$} \\
\hline & $\begin{array}{l}\text { Water- } \\
\text { Mixed } \\
\end{array}$ & $\begin{array}{l}\text { Alcohol- } \\
\text { Mixed }\end{array}$ & Both & & & \\
\hline \multicolumn{7}{|l|}{ Ethnicity } \\
\hline Yoruba & $36(42.4 \%)$ & $29(34.1 \%)$ & $20(23.5 \%)$ & 18.356 & 4 & 0.001 \\
\hline Hausa & $0(0.0 \%)$ & $0(0.0 \%)$ & $2(100 \%)$ & & & \\
\hline Igbo & $3(25.0 \%)$ & $0(0.0 \%)$ & $9(75.0 \%)$ & & & \\
\hline \multicolumn{7}{|l|}{ Religion } \\
\hline Christian & $22(41.5 \%)$ & $12(22.6 \%)$ & $19(35.8 \%)$ & 3.006 & 4 & 0.557 \\
\hline Moslem & $15(35.7 \%)$ & $16(38.1 \%)$ & $11(26.2 \%)$ & & & \\
\hline Indigenous religion & $2(50.0 \%)$ & $1(25.0 \%)$ & $1(25.0 \%)$ & & & \\
\hline \multicolumn{7}{|l|}{ Education } \\
\hline $\begin{array}{l}\text { No formal } \\
\text { education }\end{array}$ & $0(0.0 \%)$ & $1(100 \%)$ & $0(0.0 \%)$ & 22.008 & 10 & 0.015 \\
\hline Primary level & $4(50.0 \%)$ & $1(12.5 \%)$ & $3(37.5 \%)$ & & & \\
\hline Secondary & $13(43.3 \%)$ & $9(30.0 \%)$ & $8(26.7 \%)$ & & & \\
\hline $\begin{array}{l}\text { National certificate } \\
\text { in } \\
\text { education/ordinary } \\
\text { national diploma } \\
\text { level }\end{array}$ & $7(35.0 \%)$ & $11(55.0 \%)$ & $2(10.0 \%)$ & & & \\
\hline $\begin{array}{l}\text { Higher national } \\
\text { diploma/bachelor's } \\
\text { degree }\end{array}$ & $11(31.4)$ & $6(17.1 \%)$ & $18(51.4 \%)$ & & & \\
\hline $\begin{array}{l}\text { Master's or } \\
\text { doctorate degree }\end{array}$ & $4(80.0 \%)$ & $1(20.0 \%)$ & $0(0.0 \%)$ & & & \\
\hline
\end{tabular}




\section{Diagnosis and Composition of the Jedijedi Herbal Medicine}

One of the herbal vendors explained the composition of the herbal drink, although she did not give the full content of the herbal remedies for hemorrhoids. The composition is customer based: She explained that the customer's demand would determine the composition. This shows that customers participate in determining what kind of herbal treatment they receive. In the oral diagnosis, the herbal vendors would require customers to share their experience. During such conversation, the herbal vendor would understand the condition and the expectation of the customers. To the herbal vendor, most customers have expectations about the effect of herbal medicine. This demonstrated a belief that a particular kind of drug reaction would generate a specific result. Some customers might want to stool after using herbal medicine. Expectedly, the vendor would prescribe a combination of herbal medicine to meet the customer's health needs. However, if a customer's expectation was not met, this could suggest that the herbal vendor had not gained mastery of the art of herbal medicine for hemorrhoids. One of the herbal vendors gave a vivid explanation:

Herbal medicine is a long cord (Oogun gun). An individual has his/her own limit and extent of knowledge. Some will use a honey mixture, some a pineapple mixture for the piles. If someone asks for jedijedi herbal drink that it will allow stooling, I can give him/her the pineapple mixture and powder. (IDI/female/herbal vendor/Yoruba/Oyo Town/Oyo State)

Also, the diagnosis would determine the dosage to be used and how long the customer would take the mixture. Herbal vendors reportedly exposed the fact that there are dosages for herbal medicine that run contrary to general opinion. In herbal medicine for piles, for example, there are oral, anal, and nonconsumption therapies. The oral herbal medicine is usually measured in a defined quantity, although there are various prices for various measures that are still intended for one-time usage. How much the customer could pay would affect the quantity used. But if cost were not an issue, then a sufficient quantity could be prescribed. The oral herbal medicine includes the herbal drink, powder, and cigarettes. Presently, the efficacy of cigarettes for hemorrhoids remains uncertain. Also, herbal vendors experienced customers' refusal to adhere to prescriptions. Customers overuse or underuse the herbal medicine, which may have adverse effects or unsatisfying outcomes. Similarly, herbal medicine is recommended to be used for a specific duration. One of the herbal vendors explained how her experience could give the specific side effect of using:

There are negative side effects in consuming an excess of herbal medicine, although it is not much. Those herbal medicines have measurements that we must consume. For instance, if one was told to take one short cup of herbal medicine. But, say, an individual decided to take a big cup, probably because of the severity of the illness. The person may decide to take more than prescribed. Definitely, it will affect the person. That is the challenge. (IDI/female/herbal vendor/Yoruba/Ibadan/Oyo State)

In the cases in which hemorrhoids protruded, with or without relapsing, anal and nonconsumption therapies were recommended. In anal and nonconsumption therapies for piles, there are two types of herbal medicine: herbal powder and soap. A quantity of herbal powder would be portioned into three. One portion be used orally; one would be used to push the protruding anus inside, and the third portion would be poured on the customer's feces. This is a three-in-one therapy. The herbal vendors claimed that there was a particular soap that the customer would use to clean up after stooling. One of the herbal vendors gave a comprehensive explanation of the treatment.

This depends on the kind of explanation the person has given. Some explanation will prompt me to give such a person medicine to put on the person's feces. Some people now hawk a soap which the individual with piles will use to wash his/her hand. They know how they do it, but we do not know how they do it. I can give medicine to an individual who has a protruding 
hemorrhoid which such individual will use to push the piles back into the body and it will disappear; but the one we give to the individual to put on the feces or to push it in are not working for people who are not having the protruding anus. Anyone whose pile has got to the protruding stage is given such remedies. (IDI/female/herbal vendor/Ogbomoso/Oyo State)

Other discussions with the herbal vendors suggested that majority of respondents did not make a necessary enquiry about the other available therapies and procedures. This could explain why many of their customers were aware of herbal drinks and powder only.

\section{Diagnosis and History of Drug Use: Herbal Vendor Reports}

During oral diagnosis and other conversations between the herbal vendors and their customers, the vendors could decipher the history of treatment previously used by the customers to curtail the hemorrhoids episode. The vendors pointed out that many of their customers used home treatment. The customers prepared herbal drinks at home or asked herbal vendors to prepare it for them. Some of the customers would prevent hemorrhoids by taking herbal drink daily, especially in the morning, because they believed that they were constantly exposed to the risk factors. Perhaps, the home treatment was a good option for people with strict engagement. The tendency to dilute the herbal drink with alcohol would depend on targeted consumers. Alcohol would not be used especially where children are likely to ingest the herbal mixture. For instance, some of the customers prepared nonalcoholic herbal treatment for the household. Thus the household was expected to use the herbal medicine daily because every household is predisposed hemorrhoids owing to dietary habits. The daily consumption of the herbal mixture was to prevent the disease. One of the herbal vendors expressed her concern about the inevitability of the disease:

People cannot do without consuming the common food. If we would not consume the common food, it means, we would not take tea, if we would not consume the food, we would not take pap. Some people cannot do without pap per day, or tea; even rice causes piles. If we assemble a hundred people together, hardly would you find five people who do not take rice. So there is no way to avoid those things to prevent piles. (IDI/female/herbal vendor/Yoruba/Ogbomoso/Oyo State)

Consequently, herbal vendors prescribed home stocks of herbal remedy for hemorrhoids.

Some parents administered herbal medicine to their children. According to the parents, these children must have eaten sugary substances, such as biscuits and sweets. Thus, the children were given herbal drink instantly to counteract an impending hemorrhoid episode. Also, the herbal vendors asserted that children suffered from piles and lactating mothers could predispose their infants to hemorrhoids through breastfeeding. For instance, one of the herbal vendors maintained that "even little children are affected because of what the mothers eat. The moment they suck during breastfeeding, they come down with pile. Then they would be given jedijedi drink" (IDI/female/herbal vendor/Yoruba/Oyo Town/Oyo State).

\section{Discussion}

Currently, female vendors dominate the sales of herbal medicine for piles. Apart from the previous itinerant style of meeting their customers (Olateju, 2009), herbal vendors presented their herbal products in shops popularly known as joints in the study area. Such a location may explain why men usually gather in the place. The men believed that hemorrhoids would affect men more than women, especially during sexual activities. Given that men believed they were more susceptible to hemorrhoids, culturally, women were not expected to be found in such a public sphere. 
In the conception and diagnosis, both the vendors and the majority of their customers disagreed with the belief in the preternatural etiology of hemorrhoids. The respondents reportedly believed that it was a behaviour-induced disease. This suggests that the disease is inevitable for human beings. Similarly, herbal vendors and their customers upheld the misconceptions about the hemorrhoids as identified previously (Lohsiriwat, 2015). They identified all staple foods, especially sugary substances, as a major cause of the disease. Similar misconceptions were found among the police in Oyo State (Azeez \& Isiugo-Abanihe, 2017). Such ideas imply continuous management of the disease because their customers could not adopt preventive measures holistically, that is, abstinence from all staple foods. Also, the herbal vendors' diagnosis and definition of hemorrhoids included dysentery. Possibly, the herbal vendors and their customers believed that hemorrhoids share similar symptoms with dysentery. The two groups did not perceive hemorrhoids and dysentery as different diseases. Thus, the mixed-methods approach clearly exposed the inability of herbal vendors and their customers to clearly differentiate between two or more disease conditions that may coexist.

A majority of the respondents believed that hemorrhoids precluded their sex enjoyment; the belief was common and significant among married persons. In the interview sessions, the herbal vendors confirmed the same belief. In the stylistic advertisement of herbal vendors, the concept of Alala-Kulala (the sex maniac) accolades was introduced to describe the ability to perform better sexually after using herbal remedy for hemorrhoids (Olateju, 2009). As hemorrhoids affect the quality of life (Sun \& Migaly 2016), including sexual strength, there is a concentration of men in such joints. This explains why there was a high preference for herbal treatments for hemorrhoids among respondents (62.7\%). Thus, herbal medicine has gained a high level of acceptance from patients with hemorrhoids (Osungunna et al., 2010; World Health Organization, 2005). The herbal vendors believed that they had a full understanding of hemorrhoids, which explains their high patronage.

The present study found that preference was due to effectiveness, proximity, ease of use, and affordability. These were similar to previous findings (Azeez \& Isiugo-Abanihe, 2017; Soladoye, Adetayo, Chukwuma, \& Adetunji, 2011). Also, the preference of herbal medicine could be due to the ability to choose from a variety of mixtures. For example, one in every two customers for hemorrhoids preferred an herbal drink without alcohol while three in every 10 customers would opt for an alcohol-mixed herbal drink. Religious affiliations did not influence the choice to consume alcohol-mixed jedijedi drinks. However, the study showed that herbal vendors were selling an alcohol-mixed jedijedi drink to keep their patronage because customers constantly demanded such a mixture. This may suggest customers' level of alcoholism among the customers of the herbal vendors. Also, the herbal vendors allowed their customers to combine herbal and modern therapies. This would prevent the ability to ascertain which of the therapies was effective. The herbal vendors had mastery of herbal medicine for hemorrhoids for the desired result, and could make the customer stool when the customer demanded. But such stooling was linked to gastroenteritis (Osungunna et al., 2010), which suggests another form of stomach disorder such as ulcer.

For herbal vendors, the composition of jedijedi herbal remedy was customer specific. The vendor would prescribe a combination of herbal medicine to meet the customer's health needs. This further demonstrated that herbal medicine was effective. Herbal vendors would even recommend advanced herbal medicine for protruding hemorrhoids. The study also revealed that herbal medicine had a measure for an individual, which was contrary to the "no dosage" assumption (Osungunna et al., 2010). In the assumption, it was believed that herbal medicine lacked of dosage and it was not standardized. Also, the measure might not be universal; however, each customer was reportedly advised on quantity to be consumed at the point of purchase. Conversely, most of the customers did not adhere to the vendor's advice on dosage. The advice probably emanated from an informal discussion. 
The herbal vendors identified both oral and anal treatments of piles; herbal soap, jedijedi cigarettes, and a magical jedijedi powder were mentioned. These three herbal remedies have not gained recognition like the herbal drink. However, one vendor claimed that they were effective and they were meant for the customer with a critical condition. Oral herbal medicine includes an herbal drink, a powder, and cigarettes. Studies have yet to confirm the efficacy of the soap, cigarettes, and the magic powder as remedies for hemorrhoids. Soladoye et al. (2011) claimed that several plants may be efficacious in the treatment of hemorrhoids. The herbal vendors revealed that many of their customers used herbal medicine for the piles in their homes. The vendors sold it to customers upon request, for family use. The combination of the herbs would be arranged in a container, usually a plastic bottle. The family members were encouraged to use the drug daily. This serves as a prophylactic activity for the inevitability of hemorrhoids.

\section{Limitation of the study}

This study cannot be generalized to other populations because it shared unique and in-depth experiences of the local herbal vendors and their customers in health-belief dynamics. However, this kind of ethnographic study could be conducted among indigenous populations who are patronizing herbal vendors and herbal medicine. This would engender cross-cultural diagnosis and explanations of hemorrhoids.

\section{Conclusion}

There are misconceptions about hemorrhoids, herbal vendors, and their customers in the Ibadan metropolis. The misconceptions about hemorrhoids are evident in its associated causes, symptoms, and perceived effects, which are embedded in the sociocultural explanation of hemorrhoids. A low level of awareness necessitated the kind of diagnosis and management of hemorrhoids among the herbal vendors and their customers. Customers understand the risk factors and effects of hemorrhoids and that the therapies may be of no effect. Also, a heuristic platform should be established for both herbal and modern practitioners to develop a synergy to combat misconceptions about hemorrhoids to maximize potentials in herbs for the treatment of piles.

\section{References}

Akanle, O., Adesina, J., \& Fakolujo, O. E. (2017) Jedijedi: Indigenous versus Western knowledge of rectal haemorrhoids in Ibadan, Southwestern Nigeria. African Studies 76, 530-545. doi:10.1080/00020184.2017.1372121

Alatise, O. I., Agbakwuru, A. E., Takure A. O., Adisa A. O., \& Akinkuolie A. A. (2010). Open hemorrhoidectomy under local anesthesia for symptomatic hemorrhoids: Our experience in Ile-Ife, Nigeria. African Journal of Health Science, 17, 42-46.

Azeez, A., \& Isiugo-Abanihe, U. C. (2017) Sociocultural context and determinants of treatments for hemorrhoids among the Nigeria Police Force, Oyo State Command. Journal of Social, Behavioral, and Health Sciences, 11, 31-46. doi:10.5590/JSBHS.2017.11.1.02

Cleator, I. G. M., \& Cleator, M. M. (2010). The long-term results of hemorrhoids band using the O’Regan disposable suction liga. Vancouver, Canada: Scott Morrison Investments.

Coleman, J. S. (1990) Foundations of social theory. Cambridge, MA: Belknap Press of Harvard University Press.

Concordia University Health Services. Stress management: A practical guide. Retrieved May 6, 2013, from http://health.concordia.ca 
Kaidar-Person, O., Person, B., \& Wexner, S. D. (2007). Hemorrhoidal disease: A comprehensive review. Collective Reviews, 204, 102-117.

Lohsiriwat, V. (2015). Treatment of hemorrhoids: A coloproctologist's view. World Journal of Gastroenterology, 21, 9245-9252.

Ohning, G. V., Machicado, G. A., \& Jensen, D. M. (2009). Definitive therapy for internal hemorrhoids: New opportunities and options. Reviews in Gastroenterological Disorders. 9, $16-26$.

Olateju, A. (2009). Jedi O M'Akowe (Hemorrhoid respects not even the educated elite): A sociolinguistic-stylistic analysis of the language of Yoruba herbal medicine practitioners. In A. Ojo \& L. Moshi (Eds.), Selected proceedings of the 39th Annual Conference on African Linguistics (pp. 156-165). Somerville, MA: Cascadilla Proceedings Project.

Omole, M. K., \& Adegboye, O. O. (2012). A ten year study of the management of hemorrhoids at a secondary nursing home in south west Nigeria. International Research Journal of Pharmacy, 3, 198-200.

Oreagba, I. A., Oshikoya, K. A., \& Amachree, M. (2011) Herbal medicine use among urban residents in Lagos, Nigeria. BMC Complementary and Alternative Medicine, 11, 117.

Osungunna, M. O., Oluremi, B. B., \& Talabi, I. (2010). Comparative microbial quality of Jedi drinks sold in two major cities in Nigeria. Pakistan Journal of Nutrition. 9, 769-772.

Soladoye, M. O., Adetayo M. O., Chukwuma E. C., \& Adetunji, A. N. (2011) Ethnobotanical survey of plants used in the treatment of haemorrhoids in South-Western Nigeria. Journal of Advances in Developmental Research, 2, 100-111.

Sun, Z., \& Migaly, J. (2016). Review of hemorrhoid disease: Presentation and management. Clinical Colon Rectal Surgery, 29, 22-29.

World Health Organization. (2005). National policy on traditional medicine and regulation of herbal medicines: Report of a WHO global survey. Retrieved from http://apps.who.int/medicinedocs/pdf/s7916e/s7916e.pdf

Zargooshi, J. (2008) Male sexual dysfunction in unconsummated marriage: Long-term outcome in 417 patients. The Journal of Sexual Medicine, 5, 2895-2903.

The Journal of Social, Behavioral, and Health Sciences is an open-access, peer-reviewed, online interdisciplinary journal focusing on research findings that address contemporary national and international issues. Its objectives are to (a) encourage dialogue between scholars and practitioners in the social, behavioral, and health sciences that fosters the integration of research with practice; (b) promote innovative models of interdisciplinary collaboration among the social, behavioral, and health sciences that address complex social problems; and (c) inform the relationship between practice and research in the social, behavioral, and health sciences.

Walden University Publishing: http://www.publishing.waldenu.edu 